\title{
Mujeres en revolución (1868-1874)
}

\author{
Women in Revolution \\ (1868-1874)
}

\author{
PILAR GARCÍA TROBAT \\ Catedrática de Historia del Derecho. \\ Universitat de València. \\ pilar.garcia@uv.es \\ DOI: https://doi.org/10.7203/cc.1.19039 \\ Fecha de recepción: 28/10/2020 \\ Fecha de aceptación: 27/11/2020
}

\section{Resumen}

La gloriosa revolución de 1868 trajo aires de libertad y democracia. Las mujeres, aunque no se consideró llegado el momento para que participaran de forma directa en política, se convirtieron en una fuerza importante y capaz de alterar el curso de la historia política española. Desde una óptica y con unos objetivos muy diferentes, católicas, republicanas y aristócratas defendieron sus intereses a través de los canales abiertos por la misma revolución: derechos de manifestación, reunión, petición y libre expresión. A veces incluso, al margen de la ley. A la hora de reconstruir esta etapa revolucionaria tan trepidante resulta imprescindible tener en cuenta la contribución femenina para entender los cambios en el gobierno y en las formas de gobierno.

\section{Palabras clave}

Gloriosa revolución; mujer; católica; republicana; aristócrata; sufragio; quintas; Constitución de 1869; derecho de manifestación; derecho de reunión; derecho de petición; libertad de expresión.

\begin{abstract}
The glorious revolution of 1868 unleashed a sense of freedom and democracy. Women, despite not being considered their moment to directly participate in politics, became a significant force capable to alter the course of Spanish political history. From one standpoint but very different objectives, catholic, republican and aristocrat women fought for their interests through the same channels opened by the revolution: demonstrations, meetings, appealing rights, and freedom of expression. Sometimes even outside the law. When reconstructing this revolutionary phase marked by its frenetic character, it becomes necessary taking into account this female contribution to understand changes in government and in the forms of government.
\end{abstract}

\section{Keywords}

Glorious revolution; woman; catholic; republican; aristocrat; suffrage; quintas; Constitution of 1869; demonstration right; meeting right; freedom of expression right. 


\section{El sufragio femenino en las Cortes Constituyentes. - II. La misión de la mujer: influir en el hombre. - III. Católicas, repu- blicanas y el artículo 55 de la Constitución. - IV. Conspiración femenina contra Amadeo y Serrano. - V. Epílogo. Bibliografía.}

\section{El sufragio femenino en las Cortes Constituyentes}

La revolución de septiembre de 1868 abrió un periodo en la historia política de España en el que se ensayaron, desde los vitoreados principios democráticos, todas las formas de gobierno posibles y se proclamaron libertades públicas y derechos individuales, algunos por primera vez, para todos los españoles, hombres y mujeres. Solo hubo una excepción importante: el sufragio tanto activo como pasivo quedaría vedado para ellas. Es verdad que a pesar de que algunas mujeres lo solicitaron fueron las menos. Además, la prensa que se hizo eco de estas demandas, en general se escandalizaba y burlaba de ellas cuando del derecho electoral se trataba'. En Cádiz, cuando un grupo de mujeres pidieron el derecho al voto, o en Selva, cuando unas republicanas protestaron por la ley electoral, podemos encontrar respuestas tales como la publicada en un artículo de El Cascabel: "Pero hijas mías, ¿quién os quita el derecho de elegir novio, que es lo que vosotras debéis elegir?" ${ }^{2}$. Algunas peticiones femeninas introdujeron requisitos al derecho al voto de la mujer, limitando su ejercicio como en su día lo estuvo en los hombres. Son propuestas similares a las que

1 Gil Blas, 24-9-1871.

2 La referencia a las mujeres de Cádiz en El Papelito, 8-11-1868; sobre las de Selva (Tarragona) en El Cascabel, 10-12-1868. No había cambiado mucho la opinión acerca de las mujeres interesadas en política. El movimiento feminista, aunque poco secundado, se había manifestado con anterioridad. En 1851 El Clamor Público de 9 de agosto habla de un periódico femenino Ellas, en cuyo prospecto donde se anuncian decían: "la soberanía de las mujeres se ve combatida y postergada por la tiranía de los hombres; ellos hicieron las leyes y nosotras nos doblegamos al paso de la fuerza; nos rendimos cobardemente, sin pelear y el yugo nos ahoga... ha llegado el momento de unirnos, de empuñar la pluma y de combatir...". En 1854, el 16 de septiembre, el periódico La Iberia recogía bajo el título "emancipación femenina": "desde que cuatro solteronas, aficionadas a hablar de política y alguna que otra agitadora pública, como mistris Brohonnee, se dieron a defender los derechos de las mujeres y su emancipación, andan muchas de estas que no se las puede sufrir. Ahora parece que han celebrado una reunión, en que han acordado elevar la petición siguiente: 1. Sufragio universal comprensivo de todas las mujeres de probidad. 2. Participación por iguales partes en los destinos de la nación. 3. Economías en los presupuestos del Estado, y aumento en los domésticos. 4. Reforma del Código en la parte que concede la administración de los bienes de la mujer al marido. 5. Abolición de la pena de muerte por causas políticas a las mujeres. 6. Prohibición del libre comercio y penas severas contra el género de contrabando. 7. Extinción del celibato; unión conyugal. 8. Formación de un código criminal contra las coquetas. 9. Establecimientos de modas en todos los pueblos y aldeas, y que los figurines sean nacionales." Aunque claramente se trata de una burla hacia el movimiento de emancipación femenina deja constancia de algunas reivindicaciones que en los años de la revolución serán habituales. 
años más tarde se presentarían en las Cortes $^{3}$. Puede verse, por ejemplo, la carta de una suscriptora de La Correspondencia de España que pedía al diario que abogara para que se les concediera el derecho a votar diputados para las Cortes Constituyentes. La mujer se quejaba de que se aclamara tanto el sufragio universal sin contar con ellas. No deseaba la emancipación de la mujer, que en su opinión debía quedar sujeta a su marido; pero a su marido y a nadie más. De ahí que entendiera que las solteras y viudas mayores de 20 años y menores de 65 , siempre que supieran leer y escribir, deberían poder votar en las elecciones ${ }^{4}$. En otras ocasiones lamentaron no tener este derecho, aunque solo fuera como crítica a la inacción de los hombres. "Si las mujeres tuviéramos voto electoral, creemos que, aun considerado relativamente, sería mucha mayor la animación en los colegios electorales los días de votación", se recogía en un periódico satírico ${ }^{5}$. En una exposición contra la libertad de cultos presentada al general Serrano por las marquesas Santiago, Zugasti y Portugalete y firmada por 15.000 mujeres de Madrid, expresaban:

No pedimos gracia, ni imploramos clemencia. Excmo. Sr., demandamos justicia, reclamamos respeto y protección a nuestros derechos de católicas, de españolas y de mujeres. Si tuviéramos voto en los comicios, o asiento en las Cortes, allí acudiríamos a defender, aun a riesgo de nuestras vidas, la religión perseguida, la paz de las familias amenazada, la fe y la honra de España escarnecidas; pero no tenemos sino lágrimas para llorar y voces con que clamar, y por eso enviamos a V. E. lágrimas y suspiros, pidiendo lo que nosotras tenemos derecho a pedir, lo que $\mathrm{V}$. E. tiene obligación de respetar y proteger...6

Estas protestas, sin embargo, cayeron en saco roto. No había llegado aún el momento para que les fuera reconocido este derecho. La Constitución de 1869 no las tuvo en cuenta. No obstante, si nos atenemos al dictado literal del art. 16 resulta con todo discutible su exclusión: "ningún español que se halle en el pleno goce de sus derechos civiles podrá ser privado del derecho de votar en las elecciones de senadores, diputados a Cortes, diputados provinciales y concejales". ¿No eran las mujeres, españolas? Lo pondría de relieve el diputado Palanca durante el debate del proyecto de Constitución ${ }^{7}$. En su opinión, las leyes no debían dejar lugar a dudas ni interpretaciones y al recoger el proyecto "ningún español", la comisión incluía a las mujeres que eran también españolas. Según el art. 1.1. españoles eran "todas las personas nacidas en los dominios de España" por lo que las mujeres, si habían nacido en España, tenían que ser consideradas españolas y como tales, con derecho al voto. Ciertamente la inclusión de la coletilla "en pleno goce de sus derechos civiles" en el art. 16 limitaba

3 En 1877 algunos conservadores presentaron una enmienda al proyecto de ley que restablecía la ley electoral de 1865 con el propósito de que "las madres de familia, viudas y mayores de edad" pudieran gozar "del derecho electoral (...) debiendo emitir su voto por escrito o por medio de apoderado", Diario de sesiones de Cortes. Congreso de los Diputados [en adelante DSC, CD], 30-5-1877, 506. En 1907 los republicanos pedían el voto de las mujeres viudas o solteras emancipadas, mayores de 23 años, aunque solamente para las elecciones municipales, DSC, CD, 27-6-1907, 813-814; los demócratas, por su parte, proponían que pudieran votar las viudas que contribuyeran con más de 100 pesetas, Diario de sesiones del Senado, 16-71907, 1.

4 La Correspondencia de España, 26-10-1868.

5 La Madeja política, 1-8-1874.

6 La Guirnalda, 16-1-1869, 207.

7 Diario de sesiones de las Cortes Constituyentes [en adelante DSCC], 20-4-1869, 1216. 
este derecho, pero solo afectaba a algunas, no a todas. Palanca proponía junto a otros diputados enmendar el texto añadiendo las palabras "varón mayor de 20 años", para determinar al "español" al que se refería el artículo.

Todo español, varón, mayor de 20 años, que no se halle inhabilitado por sentencia ejecutoria para el ejercicio de los derechos políticos, tendrá el de concurrir con sus sufragios a las elecciones de los representantes en las Cortes, Diputaciones provinciales y ayuntamientos ${ }^{8}$.

Le contestó Segismundo Moret: la palabra español, aunque común a ambos sexos, cuando se reducía a uno de sus sentidos resultaba innecesario y superfluo especificar el género. Se sobreentendía que se refería al varón de la misma forma que cuando el art. 28 hablaba de la obligación de todo español de defender la patria se refería también solamente al hombre ${ }^{9}$. Se acabó la discusión. Sin embargo, a pesar del escaso tiempo que dedicaron a la cuestión, dejaron patente la opinión que sobre la participación directa en la política por parte de la mujer existía entre los diputados. Palanca, de pasada, afirmaba que no le importaría que la mujer tuviera derecho a votar "porque representa un progreso en el porvenir". Pero su intención no era introducir este debate, ni rebatir un sufragio llamado universal a pesar de ser exclusivamente masculino, solo pretendía introducir precisión en el texto constitucional, dejar claro que las mujeres quedaban excluidas y sobre todo rebajar la edad para poder votar.

Moret al contestarle daría con la clave del pensamiento general: "dice S. S. que puede haber duda desde el momento que se declare (si es que esto ha de hacerse en el progreso de las ideas), que las mujeres deben tener derecho electoral; pero está tan lejana esa época, es tan difícil prever ese caso, que creo no dará nunca origen a anfibologías" ${ }^{\prime 10}$. En realidad, Moret estaba plasmando la opinión de la mayoría de la sociedad, como iremos analizando. Ni en las Cortes, ni en el gobierno, ni en los revolucionarios más radicales, ni mucho menos en la mayoría de las mujeres había dudas al respecto. La idea de que las mujeres pudieran ejercer el derecho al sufragio en aquellos momentos resultaba todavía, como decía Moret, muy lejana. La enmienda no se tuvo en consideración por 141 votos contra $57^{11}$. Y no es que los 57 diputados que votaron en contra estuvieran a favor de corregir del texto del artículo la inclusión de la palabra "varón", lo más importante para ellos era otra parte de la enmienda al artículo, la que aludía a la edad para poder votar. Proponían 20 años en lugar de los 25 que disponía la comisión.

Con razón, una republicana que llamaba a la emancipación de la mujer, pudo decir que en España, a diferencia de lo que estaba ocurriendo en otros países, "nuestros ministros de gobernación no han tenido que refutar ninguna proposición de los diputados de la minoría que tendiera a elevar la situación política de las mujeres". Acababa, de forma sarcástica, diciendo: "no lo decimos en tono de reproche bajo el punto de vista de la idea sino porque a nadie se le ha ocurrido en las Cortes ser galante con las damas"12.

8 Enmienda presentada por Eduardo Palanca, Gonzalo Serraclara, Pedro José Moreno, Eduardo Chao, Joaquín Gil Berges, Adolfo de la Rosa y Emigdio Santa María. DSCC, 20-4-1869, 1210.

9 DSCC, 20-4-1869, 1218.

10 DSCC, 20-4-1869, 1219. La cursiva es mía.

11 DSCC, 20-4-1869, 1220.

12 La Federación, 28-5-1871. La referencia a la "galantería" en el texto es debida a que la autora critica también las expresiones al "bello sexo", "mitad más hermosa del género humano" que solo recubren de oro las cadenas de las mujeres. 
Todavía en el debate sobre el sufragio universal en las constituyentes de 1869 hubo más referencias interesadas sobre la mujer. A pesar de que las nuevas Cortes eran el resultado de una revolución en la que el sufragio universal había sido una de sus banderas; a pesar de que sus diputados habían sido elegidos mediante ese sufragio universal decretado el 9 de noviembre de 1868 por el gobierno provisional, en el debate constitucional se cuestionó la conveniencia de tanta universalidad, aunque solo fuera masculina. Las razones no eran nuevas. Entre ellas, la vieja idea de que la mujer pudiera acceder al derecho del sufragio suponía motivo suficiente para limitarlo en los hombres y exigirles determinados requisitos. En las constituyentes de 1854-56 ya se había utilizado como excusa para atacar el sufragio universal masculino.

Todas las escuelas conocidas, todas, sin exceptuar la que recomienda y sostiene el sufragio universal -contestaba el diputado Corradi al diputado García López- han reconocido la conveniencia de exigir estas garantías a los que aspiren al derecho de los electores (...) Los partidarios de esa escuela a que S.S. pertenece -la del sufragio universal- excluyen con inexorable rigor a una parte del género humano, cuales son las mujeres ¿Y por qué? Porque reconocen, y no podían menos de reconocerlo, que a pesar del grande y legítimo influjo que la mujer tiene en el hogar doméstico y en la suerte de las sociedades humanas, como compañera inseparable en nuestras desgracias y prosperidades, por su organización, por sus condiciones especiales y por los cuidados a que la destina la naturaleza, no tiene todo aquel criterio que se necesita para elegir bien, para tener participación en el sufragio ${ }^{13}$.

La exclusión de las mujeres, aceptada por todos, le bastaba al diputado Rivero Cidraque para negar la posibilidad misma de la existencia del sufragio universal. La naturaleza de la mujer impedía el reconocimiento de dicho derecho.

En las constituyentes de 1869 pretendiéndose la proclamación de la más amplia tabla de derechos y libertades, la mujer volvía a adquirir en los debates un protagonismo ni pretendido ni mucho menos favorable a sus derechos políticos. Volvía a ser la excusa perfecta para quienes aspiraban a limitar el derecho al sufragio. Aunque en esta ocasión el debate sería más complicado. Los derechos individuales se concebían para demócratas y republicanos como derechos naturales e ilegislables. Superiores a la legislación, eran propios del hombre, como el respirar; no eran derechos políticos. Para Castelar, "esos derechos naturales, como la personalidad, la igualdad, la libertad, la asociación, la inviolabilidad del domicilio, etc., se han hecho siempre derechos políticos, porque los Gobiernos opresores han tratado de destruirlos para poder someter a los hombres a su capricho; ha habido necesidad de consignar en las Constituciones como derechos debidos a

13 DSCC, 24-1-1856, 10178. Para el diputado Rivero Cidraque, "el sufragio universal, señores, Ileva su condenación en su propio nombre; el sufragio universal no existe ni puede existir, puesto que en si lleva excepciones, y entre esas excepciones las hay de tal naturaleza, aceptado tal y como tiene que aceptarse, que lo hacen imposible y hasta absurdo. Si a un ser viviente solo por ser hombre y porque tiene 21 años se le concede sin ninguna otra prenda de garantía el sufragio, ¿por qué se le negáis a la matrona, madre de una numerosa familia? ¿Tiene menos experiencia, menos sensatez, menos conocimiento de las cosas del mundo la mujer de 40 años, de una vida honrada, madre de seis o más hijos, que un mozo de 20 ó 21 años que ha salido apenas del colegio? Seguramente que no. El sufragio universal es una quimera; lo que se llama sufragio universal, señores, consiste en traer la masa no inteligente para ahogar la inteligencia y eso no conduce en primer término más que a la anarquía, y en último resultado a la tiranía; y no puede ser de otra manera", DSCC, 25-1-1856, 10217. 
las leyes, los que eran debidos a la naturaleza del hombre"14. Debía desaparecer la fórmula "con arreglo a las leyes" que acompañaba a estos derechos en todas las constituciones precedentes porque su abuso había limitado en ocasiones su ejercicio hasta el punto de negarse el derecho en cuestión. La Constitución solo podía declararlos y garantizar su ejercicio, pero no reconocerlos porque eran anteriores a la misma. Para evitar restricciones en leyes posteriores se debían fijar los límites en que podían desenvolverse en el mismo texto constitucional.

Cánovas, sin embargo, partidario de recoger la fórmula "con arreglo a las leyes $^{\prime \prime 15}$, es decir, de limitar su ejercicio por leyes posteriores, se sorprendía de la conceptualización de los derechos individuales como derechos naturales o ilegislables y mucho más si se trataba del derecho electoral. Si derivaba de la naturaleza humana no se podía negar a ningún ser humano, tampoco a la mujer. Y si ésta quedaba excluida era debido a que se exigía cierta capacidad que "no admitís en la mujer, por razón de su sexo". Pero exigir una determinada capacidad implicaba considerar el derecho al sufragio como derecho político y la posibilidad de restringirlo como en etapas anteriores.

No nos detendremos en el debate sino en las referencias que, con ocasión del mismo, en estas constituyentes, se hacen de las mujeres para entender el pensamiento de los diputados salidos de la revolución. Es necesario advertir que en ningún caso se discute la posibilidad de conceder el voto a las mujeres; todo lo contrario, se sirven de estos argumentos quienes quisieron conseguir que el sufragio universal se suprimiera del título primero por el peligro que suponía la "posibilidad de que un día la utopía del sufragio de una mujer se convierta, como tantas otras, en realidad"16 e introducir algunos requisitos para que los hombres pudieran votar.

Después del discurso de Cánovas a la totalidad del articulado, sería el diputado Romero Robledo, quien abriera el turno de palabra respecto del art. 16, tras la matización anteriormente analizada de Palanca ${ }^{17}$. Para Robledo, la universalidad con que se calificaba al sufragio no podía ser tal porque dejaba "a la inmensa, a la grandísima mayoría del país -las mujeres- sin tal sufragio". Siguiendo la argumentación de Cánovas alegaba que el sufragio universal como derecho individual no podía privar a las mujeres del derecho al voto. "La mujer es inteligente, es libre, es propietaria; tiene absolutamente todos sus derechos ¿por qué no se le concede el de sufragio? (...) no encontraba otra razón (...) que la de que la mujer no tiene barbas ${ }^{\prime \prime 18}$. En ningún caso estaba abogando por el sufragio femenino. De hecho, consideraba que no había en las mujeres voluntad propia de ejercerlo basándose en las denuncias presentadas en el Congreso contra algunas mujeres que lo habían ejercido. Lo hicieron en lugar de sus maridos, imposibilitados por trabajo o enfermedad. No lo habían hecho en su nombre propio sino haciendo las veces de sus maridos ${ }^{19}$.

14 DSCC, 7-4-1869, 898.

15 DSCC, 8-4-1869, 929.

16 Salazar Sarracedo, DSCC, 20-4-1869, 1222.

17 DSCC, 20-4-1869, 1228.

18 DSCC, 21-4-1869, 1232-1235.

19 Parece ser que se presentaron en el colegio electoral de la villa de Villanueva y Geltrú varias mujeres para votar en representación de sus maridos que estaban ocupados trabajando. En Guadalajara se dio por válido el voto emitido por una mujer en nombre de su marido que estaba enfermo, alegando que dicho enfermo había manifestado su deseo ante tres testigos. En las Cortes, Romero Robledo se refirió a otra que pretendió votar por su marido que estaba enfermo y tomó estos casos como demostración de la nula voluntad de las mujeres de votar por ellas mismas, DSCC, 21-41869, 1234. Los casos reseñados en Diario de Córdoba de comercio, industria, administración, noticias y avisos, 25-12-1868. También en El Papelito, 10-1-1869 y La Esperanza, 4-1-1869. 
El diputado Romero Girón, férreo partidario del sufragio universal masculino, consideraba que a pesar de ser un derecho ilegislable no se privaba a las mujeres de él, sino que eran ellas mismas quienes lo hacían "porque quizá, y sin quizá, en mi opinión, no lo quieren ni lo pueden querer". No era misión de las mujeres determinar la política del Estado ${ }^{20}$. Pero Romero Robledo siguió insistiendo: si el derecho al voto era un derecho natural no se podía privar de él a las mujeres, aunque el fin de la mujer no fuera gobernar. No podía considerarse a la mujer adherida al marido, "hay muchas que no se casan, que tienen sus derechos, que contribuyen como los hombres a levantar las cargas del Tesoro pagando contribuciones", por qué no les iba a interesar gobernar. "¿Es posible que tenga menos independencia y menos libertad una mujer que un pordiosero?" preguntaba ${ }^{21}$. Pero la cuestión se zanjó. El sufragio universal debía recogerse en la tabla de derechos ilegislables porque había sido una conquista de la revolución y las mujeres no estaban incluidas ${ }^{22}$.

Durante el debate del proyecto de la ley electoral en 1870 se volvió a hablar de las dos limitaciones a la universalidad del sufragio: la edad y el sexo. Respecto del sexo García Sanmiguel explicaba:

Hasta hoy el derecho electoral no se ha extendido a la mujer y por más que grandes pensadores como Hippel, Hugo y Stuart Mill crean que debe ser igual en derechos políticos al hombre, sin embargo, no ha llegado aún el tiempo en que este ideal científico pueda ponerse en práctica. La mujer debe hoy estar limitada a los cuidados de la familia y a formar el corazón de sus hijos para el bien; y según dice perfectamente Arhens, así como el hombre lleva sus pensamientos y sus sentimientos a examinar las relaciones que le unen al mundo y a la humanidad, la mujer, por el contrario, concreta todas sus afecciones y sentimientos a la vida íntima de la familia. Dejemos, pues, que esta hermosa mitad del género humano permanezca encerrada en los límites naturales de sus afectos y evitémosla por ahora participar de los muchos disgustos y sinsabores que al hombre proporciona la vida política ${ }^{23}$.

De nuevo el argumento de "no ha llegado aún el tiempo...". Antes que ella estaba el bien de la familia que debía preservar. Otras leyes venían a completar el retrato de aquella mujer garante de la moral familiar. Su infidelidad al esposo o los delitos pasionales continuaron siendo castigados con penas más duras que los cometidos por hombres, según el nuevo código penal de 1870 en consonancia con la opinión mayoritaria de la sociedad. Las leyes civiles y mercantiles ponían a la mujer casada o soltera no emancipada en el mismo plano inferior que a los menores de edad. En general, no hubo interés por modificar la estructura familiar, ni siquiera entre los republicanos y krausistas a pesar de apoyar su educación y emancipación ${ }^{24}$.

En febrero de 1870 se decretó la enseñanza de la Constitución en "las Escuelas normales y en todas las públicas de primera enseñanza de la Nación". De nuevo no solo se incumplió en algunas localidades, sino que en el caso de las niñas se cuestionó. Así lo recogía El Tiempo: "no discutimos la conveniencia de que al cabo de pocos meses o de pocos días, veamos pulular un enjambre

20 DSCC, 21-4-1869, 1235-1237.

21 DSCC, 21-4-1869, 1238.

22 Sobre este debate, Espigado Tocino (2010: 164-166).

23 García Sanmiguel, DSC, CD, 22-4-1870, 7331

24 De Labra (1869) ponía de manifiesto esta incongruencia en la legislación como veremos más adelante. También puede verse en Scanlon (1986: 8, 127-131). 
de políticos de seis u ocho años, pedantes liliputienses (...) pero será un mal gravísimo para las familias que las mujeres aprendan desde niñas los derechos individuales e ilegislables" ${ }^{25}$.

\section{La misión de la mujer: influir en el hombre}

Quienes se preocuparon por mejorar la situación de la mujer incidieron sobre todo en la necesidad de su instrucción. El 2 de febrero de 1869 se inauguraba con este fin El Ateneo de Señoras cuyo objetivo era afianzar la revolución procurando a través de la educación mejorar su situación en el ámbito laboral, así como liberarlas de "beaterías, palanca de reacción" ${ }^{26}$. Unos días más tarde, la Universidad de Madrid organizaba los domingos una serie de conferencias sobre la educación de la mujer. En el discurso inaugural, su rector el krausista Fernando de Castro (1869: 8) avanzará la línea de pensamiento por la que caminará el resto de los ponentes: la instrucción de la mujer era necesaria para cumplir con el destino que tenía en la vida según las condiciones de su sexo, es decir para ser "madre del hogar doméstico y madre de la sociedad". Para De Castro (ibid.: 13), las mujeres deberían ir a la universidad y estudiar pero no "tanto para cultivar en sí misma la ciencia cuanto para aplicarla en el círculo íntimo de la familia" sobre todo como madres y esposas.

La Providencia la ha colocado al lado del hombre en las tres edades que recorre su vida: en la infancia, para guiar los pasos del niño; en la virilidad, para moderar las pasiones del hombre; y en la vejez, para mantener el vacilante paso del anciano (ibid.: 14).

Cuanto más perfecta fuera su educación mayor sería su influencia sobre el hombre, aunque les advertía: "guardaos, sin embargo, de pretender imponerle nada en el orden religioso, ni en el político ni en otro alguno" (ibid.: 16). Su destino era "aconsejar, influir; de ninguna manera imperar" y menos inmiscuirse en "las pasiones de partido" (ibid.: 17). Ese mismo día, el catedrático Joaquín María Sanromá dictó la primera conferencia -"la educación social de la mujer"-. Respecto de la participación directa femenina en la política consideraba, con independencia de lo que pasara en el futuro, que la sociedad no estaba preparada para tomar ese camino. Él mismo era contrario a las mujeres que seguían los debates de Cortes, discutían con hombres asuntos políticos o consumían prensa política. Para Sanromá, la mujer tenía un papel más importante en política: no debía "hacerla" pero sí influir en la que se hiciera. No debía quedarse al margen, debía estar interesada en la política como los hombres porque ella "nos da o nos niega la libertad, garantía de esos derechos individuales que debe poseer toda persona, sea cual fuere el sexo a que pertenece" (Sanromá, 1869: 19). La llamaba a instruirse para que pudiera "influir" en cuestiones como las quintas, la esclavitud, la pobreza, el librecambismo... porque "os conviene y nos conviene" ${ }^{27}$.

25 Véase decreto en Gaceta de Madrid, n. ${ }^{\circ}$ 57, 26-2-1870. En Tarragona se oponen muchos vecinos, La idea: revista semanal de instrucción pública, 25-7-1870. Cita en La Correspondencia de España, 22-1-1869. Sobre la enseñanza de la Constitución en las escuelas de niñas, véase García Trobat (2020).

26 Jagoe (1998: 120).

27 "El soldado arrebatado a los brazos de una madre anegada en lágrimas, por una razón política que sostiene esa esclavitud blanca llamada servicio militar; el otro esclavo negro, tan marido 
Francisco Pi y Margall se encargó de impartir la decimocuarta conferencia. También para este federal la mujer debía contribuir al desarrollo de la sociedad, pero no por el camino de la política porque "su misión no está fuera sino dentro del hogar doméstico" (Pi y Margall, 1869: 5). No obstante, debía estar instruida.

¿Se quiere entonces, se me dirá, que la mujer sea también política? ¿Se quiere que la mujer tercie también en las ardientes luchas de los partidos? No, a buen seguro; no creo que la mujer deba nunca mezclarse en nuestras sangrientas luchas civiles; no creo ni aún que deba tomar parte en esas manifestaciones ruidosas que de algún tiempo acá vemos entre nosotros; no creo ni que deba hacer exposiciones en pro ni en contra de tales o cuales principios que se estén agitando; pero creo, sí, que puede y debe influir en la política, sin separarse del hogar doméstico (...) Puede la mujer influir en la marcha política de los pueblos, pero ejerciendo su acción sobre su marido, su padre, sus hermanos, sus hijos si los tiene, inflamándolos en el santo amor de la humanidad y de la patria. Lo repito: en el hogar doméstico, no fuera de él, ha de cumplir la mujer su destino (ibid.: 9-10).

De nuevo se dejaba para la mujer la influencia en los miembros varones de su familia. Sería Rafael de Labra quien en estas conferencias se mostró más avanzado a la hora de esgrimir el significado de igualdad de derechos entre hombres y mujeres ${ }^{28}$ y el sinsentido que resultaba de que la ley no reconociera su derecho al voto. Las ventajas que se invocaban para el hombre servían para la mujer.

Preguntad señoras a esos hombres que hoy corren por esas calles henchidos de orgullo con los derechos que la revolución les ha reconocido. Preguntadles ¿cuál era el argumento que a sus labios se apuntaba ayer para condenar el monopolio que de la dirección de los negocios públicos ejercían ciertas y determinadas clases conocidas bajo el nombre de país legal? (De Labra, 1869: 13,16)

Si la debilidad de su sexo era razón suficiente ¿por qué el código penal le reconocía la misma responsabilidad que a un hombre y no contemplaba siquiera como atenuante su "fragilidad"? El derecho debía estar por encima del sexo. Con todo, su mayor preocupación era la situación de la mujer casada que perdía su personalidad en el derecho civil. Sin su reforma era impensable que la mujer pudiera alcanzar sus derechos políticos. No es preciso seguir sondeando la opinión de otros conferenciantes, otros autores ya lo han hecho (Flecha García, 1996: 20-28; García Romero, 2013; Bolaños Mejías, 2003) y creo que queda de manifiesto, en cuanto a la participación política de la mujer, la opinión mayoritaria de la necesidad de instrucción para influir en la familia y en la sociedad.

como el marido blanco y tan hijo como el que besáis tantas veces en la frente, y sin embargo entregado a la brutalidad de un amo porque una razón política sostiene la esclavitud en las colonias; el pobre y el desvalido, a quien una razón política hace mirar como vago y mal entretenido, como si no fuera cien veces más peligrosa y repugnante aquella otra vagancia que se arrastra por los salones; las mercancías que por una razón política no pueden entrar a veces por las costas y fronteras, impidiendo al jornalero llevar un pedazo de pan a su boca o comprar un pedazo de lienzo para cubrir las desnudas carnes de su hijo..." (Sanromá,1869: 19-20).

28 García Romero (2018) advierte en las diferentes propuestas de los conferenciantes dos propuestas de tipo de mujer. 
Para el derecho al voto aún no había llegado el momento.

En 1870 en el discurso leído en la Universidad de Santiago con motivo de la inauguración del curso académico, el catedrático Parga Torreiro se refería a las exclusiones del sufragio, dedicando la mayor parte del mismo a la menos debatida que a la vez resultaba ser la más numerosa: la exclusión femenina ${ }^{29}$. Apenas había publicista que se opusiera a ella y, sin embargo, la única causa que encontraba para no permitirle votar era el sexo. Rechazaba la idea de Duvergier según la cual la moral y el sentido común imponían esta prohibición. Realmente al publicista francés le servían sus argumentos para rechazar la idea de que el sufragio fuera un derecho natural. Para Parga no podía ser "objeto de una oposición seria y fundada". Compartía la opinión de Stuart Mill quien, en defensa del sufragio femenino, entendía que todas las personas pretendían un buen gobierno que garantizase su bienestar y "si la forma democrática supone la concurrencia de todos a designar los que gobiernen, no hay, ciertamente, por qué excluir de entre todos a la mujer, que no tiene, ni por interés, ni por moralidad, peores títulos que los que el hombre puede invocar". No podía ser un privilegio del hombre y no encontraba razones para considerar indigno que la mujer depositase en una urna la cédula electoral cuando al hombre menos apto se le permitía ${ }^{30}$.

Pero esto era la teoría. En la práctica consideraba que no había llegado el momento... No hay tras su discurso intención ninguna de reivindicar el sufragio femenino en España. El motivo era la opinión que acerca del asunto se tenía en la sociedad no solo demostrada por "las impugnaciones sarcásticas de muchos y notables escritores" que ridiculizaban a la mujer mezclada en política, sino también por parte de las propias mujeres, la parte interesada. Sería "intempestivo establecer un derecho que a la mayor parte y la no menos competente inspirase una sarcástica sonrisa, y a las que debieran ejercerlo un soberano desprecio".

Concepción Arenal (1869: 86) abogaba por la educación de la mujer y su capacidad para ocupar la mayoría de los empleos, aunque no era partidaria de que la mujer se inmiscuyera en política ni tuviera derecho a voto porque se vería "envuelta en sus persecuciones, y la familia dispersa y los huérfanos sin amparo".

Y la mujer, ser inteligente, ¿no ha de tener opinión ni influencia en una cosa tan importante como la política? Puede pertenecer a una escuela, puede tener opinión e influir en la de otros por medio de sus escritos; pero no quisiéramos que tuviera partido ni voto. ¿Le necesita por ventura para influir eficazmente al triunfo de sus ideas? De ningún modo. Cuando sea ilustrada influirá en la política, aunque no tome parte directa en ella, porque influirá en el voto del hermano, del esposo, del hijo, del padre y hasta del abuelo (ibid.).

29 La América, 13-10-1870, Discurso leído en la Universidad de Santiago con motivo de la inauguración del curso académico de este año, por el catedrático D. Salvador Parga Torreiro, 5-7. Sobre el autor véase, Valdés Hansen (2009).

30 Respondía a quienes alegaban que el papel natural de la mujer era "educar honestamente a su familia y dedicarse a las labores domésticas". Porque no solo no afectaba a todas las mujeres sino que además podía compatibilizarse. Además, "ni la ley es la llamada a señalar al individuo los trabajos en que haya de ocuparse, ni tampoco es exacto que la mujer haya nacido exclusivamente para regir el interior de su casa, para hilar y coser las ropas de la familia". Ponía como ejemplos patrios a Santa Teresa de Jesús, Beatriz de Galindo, Luisa y Ángela Sigen, Catalina Badajoz, Luisa Medrano, la duquesa de Béjar... Respondía también a quienes consideran que podría perturbar la tranquilidad familiar cuando no estuvieran de acuerdo el matrimonio en el sentido del voto y a quienes consideraban que atentaría contra las costumbres. 
Como Arenal, Faustina Sáez de Melgar, fundadora del Ateneo de Señoras y directora de la publicación La Mujer, entendía que había que propagar "en nuestro sexo las ideas de progreso que han hecho de la mujer inglesa y norteamericana una mujer fuerte, independiente, instruida, digna sin apartarse de los deberes que la encadenan al hogar, por los lazos sagrados del amor y de la familia" ${ }^{\prime 31}$. Reivindica una instrucción sólida y provechosa que les haga conocer sus derechos y deberes, y con ellos, la noble misión que está llamada a desempeñar en el seno de la familia y de la sociedad ${ }^{32}$. Siempre vinculada a la familia. Después de alabar la tarea llevada a cabo por Faustina Sáez de Melgar, Ramón García Sánchez, en un larguísimo artículo, acababa concluyendo: "La mujer, reina de su casa, no debe aspirar sin embargo, a igualar sus atributos con los del hombre. Que avance la humanidad cuanto quiera por la senda de la civilización, ella no debe ambicionar otros derechos que los que hoy posee, si desea conservar la adoración que el hombre le profesa. El día que se igualara con este interviniendo en la cosa pública, sería el último de su felicidad, porque en ella vería el hombre un rival más de su ambición y de su egoismo. No; la mujer ha nacido para sentir y amar en la tranquilidad del hogar doméstico"33. Sin embargo, hay quienes, como el federal Juan Marín y Contreras, consideraban la necesidad de su instrucción como paso previo al ejercicio de los derechos políticos y civiles ${ }^{34}$.

También las mujeres vinculadas al republicanismo y al internacionalismo se manifestaron, en la prensa y en los mítines, en favor de la emancipación de la mujer, subrayando sobre todo la necesidad de una instrucción alejada de la influencia de la religión... ${ }^{35}$. El problema de la mujer no era su naturaleza sino su falta de instrucción que la tenía sometida. Había que desterrar esas ideas de que la mujer solo servía para "hacer chiquillos" ${ }^{36}$ y animarlas a asociarse para reclamar como los hombres sus derechos pisoteados... y ocupar su puesto en la vida social" ${ }^{\prime 37}$. No piden el derecho al sufragio sino liberarse de la tiranía a la que la religión, las leyes y la familia las han sometido ${ }^{38}$. Es decir, como apunta Alda Blanco (1998: 450), para la mayoría el sufragio quedaba relegado a un segundo lugar. No se aspiraba sino a la emancipación de la mujer, que ya era mucho. Una emancipación no solo de la familia sino también, como demandaban las internacionalistas, de los abusos del patrono en el ámbito laboral ${ }^{39}$.

\section{Católicas, republicanas y el artículo 55 de la Constitución}

A pesar de quedar excluida del sufragio y por tanto de una participación directa en política, las mujeres en esta época tendrán un protagonismo decisivo en muchos cambios políticos ${ }^{40}$. Como decía el diputado Palanca, en todos

31 La Mujer, 8-6-1871.

32 La Mujer, 24-8-1871.

33 "La Mujer. A doña Faustina Sáez de Melgar", La Iberia, 13-4-1870.

34 "Emancipación de la mujer", El Centinela de Aragón. Periódico republicano federal, 23-4-1868.

35 Un estudio sobre ellas en Sanfeliu Gimeno (2020).

36 La Federación, 28-5-1871.

37 La Federación, 20-2-1870.

38 La Federación, 31-7-1870.

39 Véase Espigado Tocino (2002).

40 Existe una amplia bibliografía sobre la participación de las mujeres en la política del siglo XIX que puede consultarse en Espigado Tocino (2015). También es interesante la que recogen Benso Calvo y González Pérez (2007). 
los pueblos siempre había mujeres dispuestas a cualquier "algazara"41 o como repetían los diarios desde opuestas ideologías la salvación de la patria estaba en la mujer. La movilización femenina se convertirá en un arma aprovechada y reprobada al mismo tiempo. Esa mujer, tenida como madre, como esposa o como hija es animada por los republicanos para pedir la supresión de las quintas, la abolición de la esclavitud o de la pena de muerte y por los neocatólicos para manifestarse o presentar exposiciones contra la libertad de cultos o el matrimonio civil. Siendo criticados estos manejos según la cuestión defendida. Así La Época recogía: "no sabemos por qué los sentimientos de la mujer que muchos diarios liberales y todos los democráticos juzgan tan respetables y atendibles cuando las impulsan a pedir la supresión o modificación de las quintas, no lo han de parecer igualmente cuando las mueven a levantar su voz en apoyo de ancianas y desvalidas religiosas, o de la conservación de iglesias y templos" ${ }^{\prime 2}$. En La Discusión, que llamaba a las mujeres a manifestarse contra las quintas, se criticaba sin embargo que en Zaragoza una mujer y un cura estuvieran repartiendo proclamas para alterar el orden. "Los neos ya no se contentan con engañar a las mujeres para que firmen exposiciones, sino que las seducen para hacerlas servir de agentes perturbadores" ${ }^{\prime 3}$.

En realidad, aunque desde ambos extremos se quiso influenciar a las mujeres para que salieran de su pasividad, las acusaciones sobre los métodos de los neos llegaron al Congreso. En las elecciones de 1871 las urnas se manifestaron en contra del trono de Amadeo eligiendo a 120 diputados de oposición radical (federales) y antidinástica (carlistas). Romero Robledo señaló las coacciones llevadas a cabo por muchos sacerdotes que, abusando del confesonario y del púlpito, amenazaron en algunas partes "con privar hasta de sepultura eclesiástica a los que votaran a los candidatos ministeriales y de la absolución en los últimos momentos de la vida (...) valiéndose de la mujer para influir en los colegios electorales" ${ }^{44}$. Nocedal no rebate estos comentarios. Todo lo contrario.

¿Qué ha creído el Sr. Romero Robledo, qué le hacía alguna ofensa al partido tradicionalista, qué hacía alguna ofensa a los católicos todos con decirles que en las elecciones han influido en favor nuestro hasta las mujeres? iTriste del partido que se vea abandonado de la influencia, hasta más no poder legítima, de las mujeres!

Sabe de la importancia de la influencia de la mujer. De hecho, el Papa, como él dice, había enviado miles de cartas a mujeres de todos los puntos de la monarquía pidiendo que "perseveren con sus maridos, y que no dejen de influir por la mañana, por la tarde y por la noche, hasta conseguir el triunfo del catolicismo" ${ }^{\prime 45}$. La influencia de las católicas fue decisiva para la victoria de las candidaturas de los tradicionalistas. Como también para desestabilizar al gobierno cuando trata de llevar a cabo medidas que -consideraban- rompían la unidad de cultos o atentaban contra la religión católica: libertad de cultos, supresión de conventos, matrimonio civil...

No solo las católicas, también las republicanas salieron a la calle ${ }^{46}$. Una de las reivindicaciones más repetidas sería la abolición de las quintas. Era una

41 DSCC, 16-2-1869, 37.

42 La Época, 26-11-1868.

43 La Discusión, 19-3-1869.

44 DSC, CD, 2-6-1871, 1370.

45 DSC, CD, 2-6-1871, 1382.

46 Sobre la amplia participación de las mujeres republicanas véase, Espigado Tocino (2005). 
reclamación histórica y en la revolución de septiembre se prometió su abolición. Como exponía el diputado Soler "en el programa de Cádiz, en los manifiestos de todas las juntas, en los manifiestos de todos los pueblos, en los manifiestos de cuantos tomaron parte en la revolución, en todos ellos estaba escrito el abajo las quintas y los pueblos vieron en la bandera de la revolución la conclusión de esa contribución injusta, de esa contribución ominosa" ${ }^{47}$. Pero a pesar de las proclamas de los septembrinos, una vez establecido el gobierno provisional, se presentó un proyecto de ley llamando al servicio de las armas para el reemplazo de aquel año, es decir, volvían las temidas quintas.

Ante la perspectiva de imponer nuevamente la contribución de sangre-que el general Serrano llamaba contribución de honor- junto a la contribución de dinero, las mujeres saldrán a la calle ${ }^{48}$. ¿Tenía precio una vida? El debate del proyecto de ley sobre la cuestión estaba previsto para el día 22 de marzo. Las razones, la guerra de Cuba exigía este esfuerzo. Desde el sábado anterior muchos carteles anunciaron que las mujeres llevarían a las Cortes una petición contra las quintas. También la prensa recogía la noticia:

Hemos recibido una invitación firmada por Dámasa Ronda, María Núñez, Petra Bulzón y Joaquina Morán, citando a cuantas madres de familia quieran concurrir el lunes próximo a las dos de la tarde al salón del Prado y el sitio del Dos de Mayo, para dirigirse después pacíficamente hasta el Palacio de las Cortes, donde entregarán una petición contra las quintas ${ }^{49}$.

Y así fue. Las féminas se concentraron a las puertas del Congreso el día señalado para el debate. Teniendo el turno de palabra el diputado García López, se empezaron a escuchar murmullos, ruidos, diputados que entraban y salían del hemiciclo... Prim, ministro de guerra, interrumpió la sesión para explicar lo que sucedía: había un motín en las puertas del Congreso y había mandado reunir las tropas en los cuarteles. En esos momentos de agitación, en que el ministro repetía "esto no se puede tolerar, esto no se puede tolerar...", tomó la palabra el ministro de Fomento, Ruiz Zorrilla para ampliar las noticias y la causa de las órdenes del ministro de guerra.

Los grupos que hay alrededor de la Asamblea para imponerse, porque solo para imponerse pueden venir esos grupos en los momentos en que estamos discutiendo, yo no sé quién los ha traído, ni quién los ha excitado (...).

El Sr. Castelar, el Sr. Sorní y el Sr. Blanc, dignísimos Diputados de la minoría

47 Soler, DSCC, 22-3-1869, 614.

48 Algunos ejemplos recogidos en la prensa: "Ayer hubo en Zaragoza una manifestación pacífica de mujeres, pidiendo la abolición de las quintas", El Pensamiento español, 7-1-1869; "El domingo a las tres de la tarde se verificó en Reus una manifestación de mujeres, a favor de la abolición de quintas y matriculas de mar. Estas manifestaciones son las que debían aconsejarse a las mujeres españolas, y no engañarlas miserablemente haciéndoles firmar exposiciones sobre lo que no entienden, convirtiéndolas en instrumento de bastardos fines", La Discusión, 14-1-1869; "El domingo último se ha verificado en Valladolid una manifestación de mujeres pidiendo la abolición de quintas. El Gobierno parece que ha mandado suspender los trabajos preparatorios de esta horrorosa contribución", La Discusión, 17-2-1869. Asistieron en Valladolid a la manifestación contra las quintas más de 300 mujeres, La Correspondencia de España, 15-2-1869. En ocasiones se trató de minimizar su participación. De la manifestación en Zaragoza La Época recogía: "grande fue el desencanto al contemplar que detrás no iba más que una treintena de mujeres, ni muy jóvenes, ni muy bellas, con banderitas rojas en las manos y dos de ellas con un estandarte en que se leía esta inscripción: República federal, ni más ni menos: abajo las quintas y matrículas de mar", La Época, 7-1-1869.

49 La correspondencia de España, viernes 19-3-1869. 
republicana, han hecho toda clase de esfuerzos y han apelado á toda clase de medios para que esos grupos se disolvieran, diciéndoles que se estaba discutiendo el proyecto, que las Cortes Constituyentes deliberarían, que los grupos habían hecho la manifestación y que podían retirarse tranquilos, rindiendo respeto a lo que las Cortes acordaran (...).

Ha habido un Sr. Diputado de la minoría republicana que en el momento en que sus tres compañeros habían conseguido que los grupos se calmaran y empezaran á disolverse, les ha dicho: «Haced lo que queráis; pero la minoría republicana es impotente en la cuestión de quintas, y nada puede conseguir contra lo que el Gobierno propone y contra lo que acuerde la mayoría.» Y entonces los grupos han continuado á las puertas de la Asamblea y se les ha excitado, porque un señor Diputado les fomentaba sus deseos de entrar aquí, no solo á imponerse, sino a arrancar, Sres. Diputados, un acuerdo por medio de la fuerza ${ }^{50}$.

La manifestación contra las quintas no era exclusivamente de mujeres pero su concurso fue muy numeroso. El periódico satírico Gil Blas explicaba que su asistencia se explicaba porque "las madres ven la posibilidad de salvar a los hijos de la odiosa contribución de sangre y acuden presurosas a manifestar su deseo" ${ }^{\prime \prime 1}$. La multitud se amontonó en las avenidas del Congreso hasta el punto que quedó interrumpido el paso por las calles aledañas. Estaban decididas a entrar en el Congreso para entregar una carta al presidente del Congreso y alcalde de Madrid, Nicolás María Rivero, con fin de conseguir su propósito. El texto de dicha misiva decía: "la comisión de señoras que piden la abolición de las quintas, solicita de la Asamblea permiso para entregar en su solemne sesión la súplica escrita que eleva a la misma, esperando de su caballerosidad dé respuesta inmediata a la manifestación que espera en las puertas del Congreso. Por la comisión, Dámasa Ronda" ${ }^{52}$.

El ambiente se volvía cada vez más hostil. Algunos diputados republicanos habían intentado calmar los ánimos. Pero de entre la multitud salían espontáneos que subidos al pórtico del Congreso pedían con vehemencia que no se disolvieran hasta que las Cortes hubiesen terminado su discusión sobre el proyecto de quintas. Uno de ellos, señalando a la puerta principal del Congreso, exclamó "que por aquella puerta, por donde en otro tiempo entraban los tiranos con gran pompa, debía penetrar en el recinto de la Asamblea el pueblo femenino, el pueblo-hembra, el pueblo-mujer, en la plenitud de su soberana majestad". Otros aprovecharon para vitorear la república ${ }^{53}$.

Cuando el general Prim dio orden para que dos batallones de la milicia acudieran al Congreso, ante la imposibilidad de disolver la manifestación, Castelar volvió a salir para pedir al pueblo que se retirase inmediatamente. La multitud empezó a marcharse, pero al prenderse a un hombre, quiso liberarlo, y se dirigió hacia la calle de Floridablanca, donde a duras penas pudieron contenerla los agentes de policía. La llegada de voluntarios logró dispersar "la compacta

50 DSCC, 22-3-1869, 622.

51 Gil Blas, 18-3-1869.

52 Parece que se permitió la entrada de la comisión en el Congreso y se reunió con Nicolás María Rivero quien manifestó que el ayuntamiento, el de Madrid, "deseoso de enjugar las lágrimas de las madres que tienen la desgracia de que a sus hijos les toque la suerte de soldado, tiene dispuesta una cantidad respetable para redimir la suerte a los mozos a quienes en la próxima quinta toque dicha suerte", El pensamiento español, 23-3-1869.

53 La Política, 23-3-1869. 
masa que formaban los manifestantes, cuya actitud en algunos momentos ha sido grave y bastante alarmante" ${ }^{\prime \prime 4}$.

El suceso, comentadísimo en todos los periódicos nacionales, abrió un debate sobre el derecho a manifestarse. Se concebía como una conquista de la revolución, pero ¿podía llegar hasta el punto de acudir tumultuariamente a las puertas del Congreso donde debatían los diputados? ¿Podía exigirse que se abrieran sus puertas para imponer cualquier medida? Para La Iberia, sería como formar junto al "congreso de los elegidos, otro de algunos electores que expresando a gritos su voluntad ciega, ejerzan coacción en el ánimo de los únicos que tranquila y serenamente pueden discutir en todas las cuestiones" Para La Época, "hoy se aboga contra las quintas y mañana se querrá destruir cualquier otra institución necesaria, siendo a todo trance indispensable que no se turbe la tranquilidad" ${ }^{\prime 56}$.

En vista de lo ocurrido, aunque quedó en nada gracias a la intervención de los diputados de la minoría republicana, la comisión de constitución creyó necesario prohibir la celebración de reuniones alrededor de las Cortes y por tal motivo, como afirmó el diputado Calderón y Herce, incluyó en el proyecto constitucional el que después sería, sin ninguna discusión aprobado, artículo 55 de la carta magna: "no se podrán presentar en persona, individual ni colectivamente, peticiones a las Cortes. Tampoco podrán celebrarse, cuando las Cortes estén abiertas, reuniones al aire libre en los alrededores del Palacio de ninguno de los Cuerpos Colegisladores" ${ }^{\prime \prime 7}$.

\section{Conspiración femenina contra Amadeo y Serrano}

La elección de Amadeo de Saboya como rey de España puso de acuerdo a carlistas, republicanos, aristocracia borbónica y neocatólicos. Todos lo rechazaron. Unos, por ser extranjero, otros, por hijo de un rey excomulgado, otros por no ser Borbón y otros, simplemente porque esperaban la proclamación de una república. La nobleza dirigió una exposición a las Cortes para que aplazaran la elección antes de designar un rey no solo extranjero sino que además comprometía los intereses de España ligándola al nuevo reino de Italia -"que había incorporado el territorio de la Iglesia y despojado al Papa de su potestad temporal" ${ }^{\prime 58}$. La mayor parte de la prensa no escatimó recursos en denigrarlo desde su llegada. El Combate por ejemplo publicaría: "Ignominia y baldón para el ciudadano español que al saber la noticia de que el rey extranjero ha manchado con su planta el suelo español, no se apresure como un león a lavarla con su sangre. Ignominia y baldón eternos para los indiferentes y cobardes, cómplices y encubridores con su indiferencia y con su cobardía, del crimen nacional"59. Adelantaba que la estancia de los nuevos monarcas no iba a ser grata. Lo que nadie podía suponer era la labor que las mujeres harían para adelantar su caída.

Como decía, los republicanos no vieron con buenos ojos a los Saboya... Sus acciones contra ellos fueron directas y las consecuencias más graves. Destaca en este sentido Modesta Periú quien publicó una hoja suelta con el título "El rey de España se va". Anunciaba el final de los viejos partidos y la pronta llegada de la república. A pesar de lo acostumbrado que estaba el público a los gritos

54 El Pensamiento español, 23-3-1869.

55 La Iberia, 23-3-1869.

56 La Época, 22-3-1869.

57 DSCC, 20-4-1869, 1212.

58 "Exposición de la nobleza contra el duque de Aosta", La Regeneración, 14-11-1870.

59 El Eco del Bruch: periódico católico-monárquico, Dios, Patria, Rey, 1-1-1871 
de los vendedores de impresos, el periódico La Época advierte la notoriedad que alcanzó el escrito de Periú ${ }^{\circ}$. No tuvo la autora la misma suerte que las damas alfonsinas que conspiraron contra el monarca. La publicación de esta proclama supuso su reclusión en la galera de mujeres. Pronto Modesta Periú cayó enferma y fue trasladada al hospital de presas por orden del médico de la galera. Aunque a iniciativa de Fernando Garrido se organizó un almuerzo para recaudar fondos para los escritores presos y sus familias, la situación de Periú empeoró ${ }^{61}$. En la prensa afín se pudo leer: "presa, enferma, encerrada donde se encierra a las criaturas más prostituidas, Modesta Periú conserva vivos, íntegros, los sentimientos de fiera independencia y el cívico entusiasmo que la han hecho distinguirse entre sus compatriotas. ¡Ojalá respire pronto el aire de libertad y vuelva con el la salud a robustecer aquel pecho donde palpitan los más nobles efectos!"62 Sin embargo, no bastaron los buenos deseos, ya que al salir en libertad le quedaba muy poco tiempo de vida. En octubre el periódico Gil Blas anunciaba su muerte ${ }^{63}$.

Fue sin duda más eficaz y menos peligrosa la labor llevada a cabo por las mujeres de alta sociedad. Ya en el siglo XX, José Francos Rodríguez (1920: 150) afirmaba que "el breve reinado de Amadeo no tuvo enemigo mayor, ni aun contando los republicanos, que el de las damas alfonsinas; eran tenaces y aún crueles". Aunque no deja de ser una exageración, ciertamente la conspiración de las señoras jugó un papel importante en su renuncia. Y con la de ellas, podríamos añadir las acciones de las republicanas, como hemos visto, aunque por motivos muy diferentes $y$, en general muchas católicas que por su cercanía a la Iglesia temieron la entronización de un rey hijo de un rey excomulgado ${ }^{64}$.

Las nobles damas alfonsinas no perdieron oportunidad ninguna para dejar en evidencia o en ridículo al monarca y a su esposa, con el fin de impedir que la dinastía de los Saboya arraigara en España. Llevaron a cabo lo que Galdós calificó como "la conspiración del desaire". Siempre que les fue posible dejaron patente sus preferencias por el príncipe Alfonso de Borbón y su rechazo hacia Amadeo y hacia su esposa. Las damas manifestaron su hostilidad hacia la monarquía "engendrada por la gloriosa" incluso antes de que la reina llegara a Madrid. Acudieron a la cárcel, con insignias borbónicas, para visitar a los oficiales que se habían negado a jurar fidelidad al nuevo monarca (Sánchez, 2019: 24). Cuando la reina llegó, una sola dama la recibió en palacio ${ }^{65}$. Y a aquellas que por cualquier compromiso tenían que tratar al rey con cierta consideración la veían con malos ojos. El paso del tiempo podría haber bastado para que aquellas mujeres hubieran quizá aceptado a los Saboya, pero el gobierno se precipitó en sus medidas contra dicha oposición y no solo aumentó aún más el rechazo, sino que además fue el medio de propaganda más eficaz para difundir los desplantes de las mujeres hacia los nuevos monarcas. Un caso bastante conocido fue la cuestión de las mantillas que llegó a convertirse en asunto principal de todas las conversaciones. Toda la prensa se hizo eco de lo sucedido no tanto por el desaire de las nobles a la reina sino, como digo,

60 La Época, 4-3-1871.

61 El Imparcial, 21-7-1871.

62 Gil Blas, 23-7-1871; La Igualdad, 12-9-1871.

63 Gil Blas,19-10-1871.

64 "Hemos interrogado a las mujeres, y nos han dicho que tienen miedo, porque esto no puede parar en bien, pues estos demonios se han empeñado en traernos un rey hereje y extranjero que España no quiere", El Papelito, 20-11-1870.

65 El Pensamiento español, 22-3-1871. 
por la torpe actitud del gobierno. Un asunto de "alta política", ironizaba $L a$ Discusión ${ }^{66}$.

El objeto principal de las conversaciones políticas no es el resultado de la elección de senadores, ni la latente crisis ministerial, ni siquiera la crisis de palacio; es la guerra de las peinetas y mantillas, que pone fuera de sí a los ministeriales haciéndoles caer impunemente en el extremo de atacar a la nobleza y censurar a las señoras, como si no tuviera ya bastantes enemigos la situación. Los ministeriales, con su intemperancia van a hacer que se generalicen la mantilla española y la peineta y que doña María Victoria no pueda salir de paseo ${ }^{67}$.

El hecho fue que varias señoras para demostrar su disgusto hacia la duquesa de Aosta se presentaron en el paseo de la Castellana ataviadas con mantillas y peinetas españolas, atuendo no muy habitual en aquel momento. Era una forma de exagerar su españolidad ante una reina extranjera y manifestarle su rechazo.

Recordando la hermosa época en que nuestros padres defendieron la independencia de la patria contra los extranjeros, han resuelto las damas honrar su memoria y hacer una protesta de españolismo, usando la airosa mantilla española y la peineta de teja. ${ }^{68}$

Al parecer, al volver a palacio el primer día de su paseo, la reina lloró ante "la actitud del Madrid elegante y aristocrático" ${ }^{69}$. Ante lo sucedido, el gobierno en lugar de quitar importancia quiso dar un escarmiento a las aristócratas. Al día siguiente, por una parte envió a la partida de la porra a la Castellana y por otra invitaron al paseo a varias mujeres de mal vivir, ataviadas con mantillas y peinetas, en carruajes elegantes acompañadas de hombres disfrazados de caballeros. Las pocas señoras que estaban en el paseo se retiraron rápidamente ante aquella ofensa ${ }^{70}$. Los periódicos ministeriales se encargaron de exagerar la cuestión insultando a las señoras en sus columnas. Pero los demás periódicos creían que no habría pasado de una mera protesta, de una "pantomima mujeril" de nos ser por la imprudencia de los ministros que lo convirtieron en un asunto de gran importancia y serias proporciones.

El resentimiento que provocó dicha cruzada del gobierno, empeoró aún más la situación hasta el punto que tenían previsto retirarse del concierto del domingo siguiente nada más los reyes hicieran acto de presencia. Por fortuna, los reyes no acudieron ${ }^{71}$. Según relataba La Correspondencia Vascongada el día de la ceremonia de apertura de las Cortes ocurrió una anécdota curiosa. Al despedirse el rey Amadeo, tras saludar a la asamblea, el general Serrano le susurró al oído: "a las señoras, para que no se piquen". El rey entonces las saludó.

66 El Eco del Bruch: periódico católico-monárquico, Dios, Patria, Rey, 2-4-1871. La Discusión, 24-31871: "Nunca pudimos sospechar que a tal punto se degradase la Revolución de septiembre; nunca hubiéramos creído que un movimiento que parecía tan grande y trascendental en un principio viniera a terminarse por una cuestión de modas y tocados (...) No comprendemos de dónde nace ese fatal empeño de dar tanta importancia a lo que en realidad no la tiene; no concebimos por qué se haya de prescindir de las grandes cuestiones políticas, sociales y religiosas pendientes para hacer política de saión o de trages".

67 La convicción, 25-3-1871.

68 El País Vasco-Navarro: jaungoicoa eta fueroac, 26-3-1871.

69 La convicción, 25-3-1871.

70 La convicción, 26-3-1871.

71 "Los duques de Aosta y las damas madrileñas", Altar y Trono, 28-3-1871, 336. 
El duque de la Torre había comprendido la importancia de su influencia tras el episodio de las mantillas ${ }^{72}$.

Pero no logró calmarlas. Los salones de las nobles se convirtieron en centros de conspiración alfonsina (Del Prado Higuera, 2016). Con ocasión de la fiesta de la Epifanía los reyes invitaron a un banquete en palacio a todos los nobles españoles. La mayoría sin embargo prefirió acudir a otra fiesta organizada por la condesa de Heredia Spinola para festejar la onomástica del príncipe Alfonso. Una verdadera recepción regia sin el rey a quien recordaron porque sufre "la consecuencia de faltas que no son suyas sino de la intolerancia y de la mala fe de los partidos" ${ }^{\prime \prime 3}$. La Época lo recordaba tiempo después.

Nadie ha olvidado el baile de las flores de lis con que se celebró el santo del entonces Príncipe Alfonso el 23 de enero de 1872 (...) la Condesa de Heredia Spinola preparó aquella manifestación pacífica de afecto y fidelidad al que viva lejos de su patria. Todas las principales señoras de la corte encargaron en las joyerías magníficas flores de lis de brillantes y (...) se presentaron en el sarao de la calle Hortaleza con lo que era a la par una protesta contra lo existente y un símbolo de adhesión a los desterrados. Quince días antes solo se hablaba en Madrid de la fiesta del 23 de enero; quince días después se hablaba todavía de ella en los círculos en los cafés y en los periódicos ${ }^{74}$.

Parte de la prensa aludió a aquella fiesta y a las flores de lis que portaban las damas $^{75}$. En otra ocasión, en la festividad del 2 de mayo sería muy comentada la ausencia de señoras en el desfile. Cuando el acto terminó, sin ninguna ceremonia, Amadeo y su esposa se marcharon a palacio en un ambiente donde solo se respiraba indiferencia y frialdad ${ }^{76}$. Son numerosas situaciones semejantes a que Francos Rodríguez hace referencia.

Las señoras principales de Madrid bullían en conspiración permanente, apareciendo siempre como las fuerzas más decisivas, más resueltas, más valientes, en el partido de Don Alfonso. La condesa de Montijo reanudó sus recepciones de los domingos, y en ellas todo se consagró a la causa del Príncipe (...) Con un gran baile inauguró la duquesa de Bailén su palacio de la calle de Alcalá y la magnífica fiesta fue un verdadero mitin alfonsino... (Francos Rodríguez, 1920: 150).

Estas conspiraciones fueron denunciadas por la prensa casi desde el comienzo del sexenio democrático pero no se atrevían a precisar demasiado. El Gil Blas animaba a dar más información sobre casas y asistentes, sabiendo que era información que no podían publicar ${ }^{77}$. Después sería el diario La Discusión

72 El Eco del Bruch: periódico católico-monárquico, Dios, Patria, Rey, 16-4-1871.

73 Basta comprobar la lista de asistentes que se publica en La Correspondencia de España, 25-11872. La cita en La Época, 24-1-1872.

74 La Época, 5-4-1886.

75 El Cascabel, 25-2-1872, censuraba la actuación del gobierno en un diálogo ficticio entre dos damas. "-¿Cuándo abre V. los salones, marquesa?; -Ay amiga, corren malos vientos y voy a emigrar; -por qué; -ayer tuve la desgracia de llevar en el peinado una flor de lis y la policía guarda hoy mi casa, porque como la partida de la porra es libre, debe aquella vigilarme. He aquí la libertad bien entendida." Otros aludían a los encargos de joyas encargadas con el motivo de la flor de lis, El constitucional, 18-2-1872; o con ironía señalaban el hallazgo de una flor de lis encontrada en el palacio de Spinola.

76 El Pensamiento español, 3-5-1872.

77 "Necesito que El Pueblo sea más explícito. Nos ha indicado ya dos o tres veces que hay reu- 
quien trataría de publicitar estas reuniones conspiratorias contra Amadeo; de su denuncia se hicieron eco muchos otros diarios republicanos ${ }^{78}$. El gobierno mandó vigilar algunas casas pero resultaba difícil denunciarlas cuando muchas de las esposas de los ministros eran las primeras en querer ser invitadas. En palabras de Varela "estaba de moda ser alfonsina".

Tras la renuncia del monarca, las damas se concentraron para acabar con la república, utilizando la misma estrategia. Cuando Serrano era el presidente de la república, las fiestas organizadas por su esposa, la duquesa de la Torre, eran contrarrestadas por otras organizadas al mismo tiempo por las cómplices de la conspiración. Como publicó José Varela Ortega (1977: 33, 77-78) hubo un ministro inglés que comentó "Ios españoles que de todo hacen chiste ya apodan a la Restauración The ladies' revolution".

Es notorio cuánto contribuyeron las damas españolas -y especialmente las madrileñas- a la Restauración de la Monarquía siendo una de las más activas, inteligentes y decididas propagandistas la Condesa de Heredia Spinola. ¡Cuántos partidarios conquistó al malogrado rey D. Alfonso con sus constantes esfuerzos, con su vivo entusiasmo, con su fe ardiente! ¿Cuántos revolucionarios se hicieron conservadores merced a su palabra calurosa, a su lógica irresistible, merced también a sus atractivos personales que estos ejercen y han ejercido grande influjo siempre en las resoluciones humanas? La Condesa no se daba punto de reposo en su empresa monárquico-dinástica, animando a los tibios persuadiendo a los desconfiados infundiendo esperanza a los incrédulos, fue eficacísima colaboradora, poderosa auxiliar en Madrid de la obra llevada a cabo en Sagunto por el general Martínez Campos ${ }^{79}$.

\section{Epílogo}

No había llegado aún el momento para que la mujer pudiera expresarse en las urnas pero no importó mucho. Su influencia bastó para poner patas arriba la política gestada por hombres. Esta parte de la historia no se puede entender sin tenerlas en cuenta. Republicanas, católicas y aristócratas, sin unirse en los objetivos a combatir, hicieron su guerra particular aunque solo las primeras intentaron mejorar su papel en la sociedad y el reconocimiento de sus derechos políticos. Solo ellas siguieron la estela del incipiente movimiento feminista en España para el que el sufragio no era tan importante como la revolución social.

Pero eso no resta mérito al resto de mujeres que viendo su modelo de vida amenazado no consintieron los cambios o procuraron la vuelta de su monarca favorito. Defendieron sus intereses a través de los canales abiertos por la misma revolución: derechos de manifestación, reunión, petición y libre expresión. Y no les importó tampoco inmiscuirse en reuniones conspiratorias, aún a riesgo de sus vidas. Como decía Francos Rodríguez:

Jamás una clase social tuvo mayor ardimiento político, ni más deseo de traducir en hechos sus inclinaciones, que la aristocrática española desde 1870 al 1874. El alma de aquella poderosa agitación fue siempre la mujer, y así las

niones alfonsinas en cierta casa. Nos ha indicado también que a las reuniones asisten personas de situación. Estas cosas no se deben decir a medias. Sepámoslo todo, porque esto interesa al país. Suplico a mi colega que nos saque pronto de la duda", Gil Blas, 22-7-1869.

78 La Discusión 23-5-1872.

79 La Época, 5-4-1886. 
de nuestra sociedad elegante dieron a los hombres ejemplos de habilidad, de tesón y de fortaleza (...) En la noche del 24 de diciembre de 1874 hubo en la casa de la Montijo misa del gallo y cena. Como siempre vibraron las expansiones de los alfonsinos, su deseo de que sonara pronto la hora definitiva. Alguien, viendo cómo despuntaba la aurora dijo en voz alta: "Llega el día". Y la condesa, mostrando el manifiesto de Sandhurst exclamó entre vítores: "No, estamos aún en la víspera" (Francos Rodríguez, 1920: 152).

En efecto, el día 30 se alzaba Martínez Campos.

No quedan en este artículo reflejadas sino algunas de las acciones de las mujeres a modo de ejemplo. Algunas señoras católicas recorrieron los pueblos de su provincia para recoger firmas a favor de la unidad católica. Las autoridades locales trataron en ocasiones por todos los medios posibles de impedirlo. Se las procesó y envió a la cárcel, se les arrebataron las hojas firmadas... pero siguieron adelante en su lucha ${ }^{80}$.

Las manifestaciones contra las quintas continuarían durante todo el sexenio. En la campaña contra las quintas recogieron firmas, organizaron manifestaciones, e incluso motines (De la Fuente Monge, 2008: 109). En Cataluña ante los sorteos previstos, las mujeres levantaron barricadas, tomaron los campanarios para tocar a rebato, e incluso se apostaron en las azoteas para disparar. En Sans el archivo parroquial quedó completamente desmantelado. Las mujeres amotinadas se llevaron los expedientes y libros parroquiales con los que hicieron una hoguera ${ }^{81}$. Las mujeres se asociaron. Organizaron suscripciones a favor de jornaleros y obreros despedidos por asistir a las manifestaciones ${ }^{82}$. Se levantaron contra los patrones en las fábricas ante situaciones injustas. El motín de las cigarreras en Sevilla, por ejemplo, se produjo cuando el director de la fábrica de tabacos notificó a las operarias que se les descontaría del sueldo en tres quincenas el importe de la cédula de vecindad. Ante esta noticia estalló el motín con más de mil mujeres. El jefe de policía que acudió a la fábrica para despejar el edificio se llevó una pedrada. Salieron a la calle gritando hasta la casa del gobernador a la que tiraron piedras, rompiendo cristales e hiriendo a un inspector. Un disparo al aire de un guardia civil acompañado de una carga de los voluntarios hizo que se dispersaran. Al día siguiente encontraron la fábrica cerrada y volvieron a manifestarse con bandera roja y gritando mueran los ladrones ${ }^{83}$.

\section{Bibliografía}

Arenal, C. (1869). La mujer del porvenir. Artículos sobre las conferencias dominicales para la educación de la mujer, celebradas en el Paraninfo de la Universidad de Madrid. Madrid: Oficina tipográfica del Hospicio.

Benso Calvo, C. y González Pérez, T. (2007). Bibliografía sobre historia de la educación de las mujeres en España. Historia de la educación, 26, 483-517.

Blanco, A. (1998). Teóricas de la conciencia femenina. En C. Jagoe, A. Blanco y C. Enríquez de Salamanca. La mujer en los discursos de género. Textos y contextos en el siglo XIX (pp. 445-472). Barcelona: Icaria editorial.

80 El Pensamiento español, 1-2-1869.

81 La Época, 11-4-1870.

82 Así lo hicieron las ciudadanas del club de Antón-Marín, cuyo consejo de dirección estaba integrado por Dámasa Ronda, presidenta, Bernarda Martínez, vicepresidenta, Ángela González, tesorera. Y las vocales, Francisca Mateo, Petra Mateo, Antonia Orenes, Eulogia Morán, Julia Baldres, María Baldres, Matilde Baldres, Joaquina Moran, secretaria, La Igualdad 2-7-1869.

83 La Correspondencia de España, 4-5-1871. 
Bolaños Mejías, C. (2003). La imagen de la mujer española durante el Sexenio: entre el cambio social y el reconocimiento jurídico. Feminismo/s, 2, 25-40.

De Castro, F. (1869). Discurso inaugural de las Conferencias dominicales sobre la educación de la mujer. Madrid: Imprenta y estereotipia de M. Rivadeneyra.

De la Fuente Monge, G. (2008). El teatro republicano de la Gloriosa, Ayer, 27 (2008), 83-119.

De Labra, R. (1869). Conferencias dominicales sobre la educación de la mujer. Quinta conferencia sobre la mujer y la legislación castellana, 21 de marzo de 1869. Madrid: Imprenta y estereotipia de M. Rivadeneyra.

Del Prado Higuera, C. (2016). Los salones de la nobleza española durante el reinado de Amadeo I, Aportes, 91, 27-56.

Espigado Tocino, G. (2002). Las mujeres en el anarquismo español (1869-1939). Ayer, 45, 39-72.

Espigado Tocino, G. (2005). Mujeres radicales: utópicas, republicanas e internacionalistas (1848-1874). Ayer, 60, 15-43.

Espigado Tocino, G. (2010). El discurso republicano sobre la mujer en el Sexenio democrático, 1868-1874: los límites de la modernidad. Ayer, 78, 143-168.

Espigado Tocino, G. (2015). Las españolas y la acción política en la historia contemporánea. Los diez últimos años de investigación. Ayer, 97, 227-239.

Flecha García, C. (1996). Las primeras universitarias en España, 1872-1910. Madrid: Narcea, s.a. de ediciones.

Francos Rodríguez, J. (1920). La mujer y la política españolas. Madrid: Librería de los sucesores de Hernando.

García Romero, J. (2013). Las conferencias dominicales en la Asociación para la enseñanza de la Mujer. Cabás, 10, 102-108.

García Romero, J. (2018). Las conferencias dominicales en la asociación para la enseñanza de la mujer: dos paradigmas humanos. Oratores, 8, 39-46.

García Trobat, P. (2020). Escuelas para niños y escuelas para niñas en el Trienio liberal. Historia constitucional, 21, 138-169

Jagoe, C. (1998). La enseñanza femenina en la España decimonónica. En C. Jagoe, A. Blanco y C. Enríquez de Salamanca. La mujer en los discursos de género. Textos y contextos en el siglo XIX (pp. 105-157). Barcelona: Icaria editorial.

Pi y Margall, F. (1869). Conferencias dominicales sobre la educación de la mujer. Conferencia decimocuarta sobre la misión de la mujer en la sociedad, 23 de mayo de 1869. Madrid: Imprenta y estereotipia de M. Rivadeneyra.

Sánchez, R. (2019). Política de gestos. La aristocracia contra la monarquía democrática de Amadeo de Saboya. Pasado y Memoria. Revista de Historia Contemporánea, 18, 19-38. Disponible en: https://doi.org/10.14198/ PASADO2019.18.02

Sanfeliu Gimeno, L. (2020). “Luchadoras por la verdad y la justicia”. Asociacionismo femenino, derechos y educación en el sexenio democrático. Historia Nova. Revista de Historia contemporánea, 18, 450-485. Disponible en: https://doi. org/10.20318/hn.2020.5114

Sanromá, J. M. (1869). Conferencias dominicales sobre la educación de la mujer. Primera conferencia sobre la educación social de la mujer. 21 de febrero de 1869. Madrid: Imprenta y estereotipia de M. Rivadeneyra.

Scanlon, G. M. (1986). La polémica feminista en la España contemporánea (18681974). Madrid: Ediciones Akal.

Valdés Hansen, F. (2009). El senador Salvador Parga Torreiro (1838-1901). Cuadernos de estudios gallegos, LVI-122, 333-370.

Varela Ortega, J. (1977). Los amigos políticos. Partidos, elecciones y caciquismo en la Restauración (1875-1900). Madrid: Alianza editorial. 